\title{
Neutrophil Adhesion in Leukocyte Adhesion Deficiency Syndrome Type 2
}

\author{
M. Laurie Phillips, *‡ Barbara R. Schwartz, ${ }^{\$}$ Amos Etzioni, ${ }^{9}$ Robert Bayer, ${ }^{\star}$ Hans D. Ochs," James C. Paulson, * \\ and John M. Harlan $\$$ \\ *Cytel Corporation, San Diego, California 92121; ${ }^{\ddagger}$ Departments of Immunology, Chemistry and Molecular Biology, Research Institute \\ of Scripps Clinic, La Jolla, California 92037; ${ }^{8}$ Division of Hematology, Department of Medicine, and "Department of Pediatrics, \\ University of Washington, Seattle, Washington 98195; and 'Departments of Pediatrics and Clinical Immunology, Rambam Medical \\ Center and The Bruce Rappaport Faculty of Medicine, Technion-Israel Institute of Technology, Haifa, 31096 Israel
}

\begin{abstract}
We have previously reported a newly discovered congenital disorder of neutrophil adhesion, leukocyte adhesion deficiency syndrome type 2 (LAD II). The clinical manifestations of this syndrome are similar to those seen in the classic leukocyte adhesion deficiency syndrome, now designated type 1 (LAD I), but the two syndromes differ in the molecular basis of their adhesion defects. LAD I is caused by a deficiency in the CD18 integrin adhesion molecules while LAD II patients are deficient in expression of sialyl-Lewis $\mathrm{X}\left(\mathrm{SLe}^{\mathrm{x}}\right)$, a carbohydrate ligand for selectins. In this report we demonstrate that neutrophils from a LAD II patient bind minimally or not at all to recombinant E-selectin, purified platelet P-selectin, or P-selectin expressed on histamine-activated human umbilical vein endothelial cells, but have normal levels of $\mathrm{L}$-selectin and CD11b/CD18 integrin, and adhere to and migrate across endothelium when CD11b/CD18 is activated. We compare LAD I and LAD II patient neutrophil function in vitro, demonstrating that integrin and selectin adhesion molecules have distinct but interdependent roles in neutrophil adhesion during an inflammatory response. (J. Clin. Invest. 1995. 96:2898-2906.) Key words: inflammation • immunocytoadherence - immunodeficiency - immunocompromised
\end{abstract}

\section{Introduction}

Recruitment of neutrophils from the blood stream to extravascular sites of inflammation is a critical event in host defense against bacterial infection and in the repair of tissue damage. In addition, under some circumstances, neutrophil accumulation may contribute to vascular and tissue injury. Studies by intravital microscopy dating back to the 19th century have identified a complex but coordinated sequence of events involved in neutrophil emigration (1). In response to extravascular stimuli such as bacterial-derived chemoattractants, or endogenous lipid and peptide mediators generated at sites of infection or tissue damage, leukocytes are first observed to "roll" along the vessel

Address correspondence to Laurie Phillips, Cytel Corporation, 3525 John Hopkins Court, San Diego, CA 92121. Phone: 619-552-3073; FAX: 619-552-8801.

Received for publication 2 August 1993 and accepted in revised form 28 August 1995.

J. Clin. Invest.

(C) The American Society for Clinical Investigation, Inc.

0021-9738/95/12/2898/09 \$2.00

Volume 96, December 1995, 2898-2906 wall adjacent to the site of inflammation. This rolling was described by Atherton and Born (2) to shear forces produced by blood flow and adhesive forces between the leukocyte and endothelium. Some of the rolling cells subsequently adhere firmly or "stick", then diapedese between endothelial cells, and migrate through the subendothelial matrix to the site of inflammation. Defects at any point in this cascade of events will impair emigration.

As with other questions in biology, important insights into the molecular basis of leukocyte adherence to endothelium during the process of migration come from studies of genetic deficiency syndromes. The leukocyte adhesion deficiency syndrome type 1 (LAD I $)^{1}$ results from a congenital deficiency of the leukocyte $\beta_{2}$ integrin receptor complex CD11/CD18 on the cell surface $(3,4)$. Patients with LAD I syndrome exhibit a profound defect in neutrophil and monocyte emigration to extravascular sites of inflammation. Studies in vivo $(5,6)$ and in vitro $(7,8)$ demonstrate that $\mathrm{CD} 11 / \mathrm{CD} 18$ and its endothelial cell ligands including intercellular adhesion molecule-1 (ICAM-1; CD54) are necessary for firm neutrophil adherence and transendothelial migration. However, leukocyte rolling along the vessel wall in vivo (6) and neutrophil adherence to endothelium in vitro (9) under conditions of physiologic shear forces were found not to be dependent upon CD11/CD18. Instead, multiple studies in vivo and in vitro indicate that the initial adhesive interaction between leukocytes and the vessel wall, manifested by rolling, is mediated primarily by selectin receptors and their glycoconjugate ligands (reviewed in references 10 and 11). Shear-resistant adhesion mediated by selectins promotes the initial slowing of leukocytes allowing subsequent engagement of integrin receptors and firm adhesion. Consequently, defects in selectin-dependent adhesion should also result in impaired neutrophil emigration to tissue. Etzioni et al. described two patients with a congenital defect of neutrophil adhesion resulting from a generalized fucose deficiency, and this syndrome has been designated LAD type 2 (LAD II) (12). In the initial report, it was shown that neutrophils from the LAD II patients did not express sialyl Lewis $\mathrm{X}$ ( $\mathrm{SLe}^{\mathrm{x}}$; CD15s ), a fucose-containing glycoconjugate ligand for E (CD62E) - , P (CD62P) - , and L (CD62L) selectins (13-15), and failed to bind to interleukin-1-treated endothelial cells expressing E-selectin. In the studies reported here, we extend these observations, demonstrating that neutrophils from a LAD II patient bind minimally or not at all to recombinant E-selectin, purified platelet P-selectin or P-selectin expressed on histamine-activated human umbilical vein endo-

1. Abbreviations used in this paper: DPBS, Dulbecco's PBS; HUVEC, human umbilical vein endothelial cells; LAD I, Leukocyte adhesion deficiency type 1; LAD II, Leukocyte adhesion deficiency type 2; Le ${ }^{\mathbf{x}}$, sialyl Lewis X; SLe ${ }^{\text {a }}$, sialyl Lewis A. 
thelial cells (HUVEC), but have normal levels of L-selectin and $\mathrm{CD} 11 \mathrm{~b} / \mathrm{CD} 18$ integrin, and adhere to and migrate across endothelium when CD11b/CD18 integrin is activated.

\section{Methods}

Antibodies. The anti-P-selectin monoclonal antibody PB1.3 (16) and the anti-E-selectin mAbs EB3.1 (IgG3) and ENB1.6 (IgG1) (Phillips, M. L., B. R. Schwartz, A. Etzioni, R. Bayer, H. D. Ochs, J. C. Paulson, and J. M. Harlan, unpublished data) were produced in our laboratory. The CD15s mAb CSLEX-1 (IgM) (17) was acquired from the American Type Culture Collection (Rockville, MD). Monoclonal antibodies Leu 8 (L-selectin, IgG2a) and Leu 11b (CD16, IgM) were purchased from Becton-Dickinson (San Jose, CA), OKM-1 (CD11b, IgG2b) from Ortho Diagnostic Systems (Raritan, NJ) and CLBgran/10 (CD66, IgG1) from Caltag Laboratories (So. San Francisco, CA). Monoclonal antibody $7 \mathrm{C} 3$ (anti-Lewis $\mathrm{X}\left[\mathrm{Le}^{\mathrm{x}}\right], \mathrm{CD} 15, \mathrm{IgG} 3$ ) (18) was a gift of Dr. D. Hickstein, University of Washington, Seattle, WA. Monoclonal antibody BS1 (CD43, IgG1) (19) was produced in our laboratory (B. R. Schwartz and J. M. Harlan). Monoclonal antibody 60.3 (CD18, IgG2a) (20) was a gift of Dr. P. Beatty, University of Utah, Salt Lake City, UT and the CD45RO Mab UCHL1, (Ig2a) (21) was the kind gift of Dr. Peter L. C. Beverly, University College and Middlesex Medicine London, United Kingdom. Monoclonal antibody HECA-452 (antihigh endothelial venule, lymphocyte homing antigen, rat IgM, recognizes $\mathrm{SLe}^{\mathrm{x}}[\mathrm{CD} 15 \mathrm{~s}]$ and sialyl Lewis A [SLe $\left.{ }^{\mathrm{a}}\right]$ ) (22) was a gift of Dr. Steven Pals, Academisch Ziekenhuls Frije Universiteit, Amsterdam, The Netherlands. Monoclonal antibody JP34-10 (CD13, IgG2a), the gift of Dr. D. Roos, Netherlands Red Cross, Amsterdam, The Netherlands, and the CDw17 mAb (antilactosylceramide, IgM; Biodesign International, Kennebunkport, ME), were used as isotype-matched neutrophil-binding control mAbs for 60.3 and CSLEX-1, respectively.

Flow cytometry. Leukocytes were prepared from $3 \mathrm{ml}$ of heparinized whole blood by repeated lysis with cold red cell lysing solution $\left(\mathrm{NH}_{4} \mathrm{Cl}\right.$ $168 \mathrm{mM}, \mathrm{KHCO}_{3} 10 \mathrm{mM}$, EDTA $0.1 \mathrm{mM}, \mathrm{pH} 7.3$ ). Unlysed cells were collected by centrifugation at $300 \mathrm{~g}$ for $5 \mathrm{~min}$. Leukocytes were resuspended at $5-6 \times 10^{6} / \mathrm{ml}$ in HBSS without calcium and magnesium (GIBCO, Grand Island, NY). One aliquot was treated with PMA (Sigma Chemical Co., St. Louis, MO) $10^{-7} \mathrm{M}$ at $37^{\circ} \mathrm{C}$ for $40 \mathrm{~min}$. Treated and untreated cells were incubated on ice with $50 \%$ heat-inactivated adult bovine serum (Hyclone, Logan, UT) and then with test mAbs.

Bound murine mAbs were stained with FITC-goat anti-mouse IgG $+\operatorname{IgM~} \mathrm{F}\left(\mathrm{ab}^{\prime}\right)_{2}$ fragments, human adsorbed (Tago, Inc., Burlingame, CA). HECA-452 mAb was stained with goat anti-rat-FITC second antibody (Tago, Inc.). Bound mAbs were visualized using a Coulter EPICS IV flow cytometer (Coulter Electronics, Hialeah, FL).

Activation of LAD II patient PMN by FMLP. Small aliquots of leukocytes prepared for flow cytometry were combined with FMLP $\left(10^{-7} \mathrm{M}\right)$ on ice. They were placed in a $37^{\circ} \mathrm{C}$ water bath and fixed after $30 \mathrm{~s}$ by addition of an equal volume of $2 \%$ paraformaldehyde and placed on ice. Cells were gated on neutrophils and changes in forward and $90^{\circ}$ light scatter were assessed by flow cytometry (23).

Preparation of histamine- or TNF-activated HUVEC adherence assay plates. The histamine-activated HUVEC adherence assay was performed essentially as described by Lorant et al. (24). Primary HUVEC were grown to confluence in $1 \%$ gelatin (Sigma Chemical Co.) coated 96-well assay plates (Costar, Cambridge, MA) in endothelial basal growth medium (Clonetics Corp., San Diego, CA) containing 2\% human serum, $50 \mu \mathrm{g} / \mathrm{ml}$ gentamicin, $50 \mathrm{ng} / \mathrm{ml}$ amphotericin B, $1 \mu \mathrm{g} /$ ml hydrocortisone, and $10 \%$ fetal calf serum (Irvine Scientific, Santa Ana, CA) but without bovine brain extract or endothelial cell growth factor. The monolayers were washed three times with HBSS containing $\mathrm{Ca}^{2+}$ and $\mathrm{Mg}^{2+}$ (Gibco), $1 \mathrm{M}$ Hepes (Gibco), $0.2 \%$ D-glucose (Sigma Chemical Co.) and 0.5\% BSA (Sigma Chemical Co.) (HBSSg/BSA). HUVEC were activated in the same buffer for $5 \mathrm{~min}$ with histamine (Sigma Chemical Co.) at $5 \times 10^{-5} \mathrm{M}$ for $5 \mathrm{~min}$. TNF- $\alpha$-activated HUVEC assay plates were prepared as above except that HUVEC were grown in the presence of bovine brain extract and endothelial cell growth factor and were activated with recombinant human TNF (R\&D Systems, Inc. Minneapolis, $\mathrm{MN}$ ) at $2 \mathrm{ng} / \mathrm{ml}$ for $4 \mathrm{~h}$ at $37^{\circ} \mathrm{C}$.

Preparation of purified E-selectin adhesion plates. A cDNA clone of the extracellular domain of E-selectin was obtained by polymerase chain reaction from RNA of IL- $\beta$-activated HUVEC (Genzyme Corp., Boston, MA). The recombinant cDNA was cloned into the mammalian expression vector pcDNA1 (Invitrogen Corp., San Diego, CA). This clone was transfected into the 293 cell line (CRL-1573; American Type Tissue Culture Collection) together with the selectable marker pSVZ neo and stable G418-resistant cell lines expressing soluble recombinant E-selectin were obtained (25). Recombinant E-selectin was purified from cell culture supernatant medium by immunoaffinity chromatography on EB3.1 immobilized on a protein A Sepharose column by the method of Schneider et al. (26). Purity of the material was determined by SDS-PAGE to be $>95 \%$.

E-selectin was bound to assay plates using the nonblocking anti-Eselectin mAb ENB1.6 as a capture antibody. Costar 96-well tissue culture cluster dishes were incubated with $50 \mu \mathrm{l} /$ well of ENB1.6 at $10 \mu \mathrm{g} /$ $\mathrm{ml}$ in PBS at $4^{\circ} \mathrm{C}$ for $24 \mathrm{~h}$. The plates were washed three times with PBS and then incubated with $50 \mu \mathrm{l} /$ well of purified E-selectin at $2 \mu \mathrm{g} /$ $\mathrm{ml}$ for $2 \mathrm{~h}$ at $22^{\circ} \mathrm{C}$. The plates were washed three times with Dulbecco's PBS (DPBS; contains $\mathrm{Ca}^{2+}$ and $\mathrm{Mg}^{2+}$ ), and then blocked with $200 \mu \mathrm{l} /$ well DPBS containing $1 \%$ BSA for $1 \mathrm{~h}$ or more at room temperature.

Preparation of purified P-Selectin assay plates. P-selectin was prepared from solubilized platelet membranes essentially as described by Moore et al. (27). P-selectin was purified from the supernatant of homogenized platelets by immunoaffinity chromatography on anti-P-selectin mAb PB1.3 coupled to tresyl-activated agarose according to the manufacturer's instructions (Schleicher \& Schuell, Inc., Keene, NH). The column was equilibrated with DPBS $+0.05 \%$ Rennex 30 (Accurate Chemical and Scientific Corp, San Diego, CA). The column was washed extensively with DPBS $+0.05 \%$ Rennex 30 , and bound P-selectin was eluted with $0.1 \mathrm{M}$ triethylamine- $\mathrm{HCl}, 0.05 \%$ Rennex $30, \mathrm{pH} 11.5$, into tubes containing 0.1 vol $1 \mathrm{M}$ phosphate, $\mathrm{pH}$ 6.8. Fractions containing P-selectin were pooled, dialyzed against DPBS $+0.05 \%$ Rennex 30 , concentrated using a Centriprep 30 spin concentrator (Amicon Corp., Danvers, MA), aliquoted, and stored at $-80^{\circ} \mathrm{C}$.

A Costar 96-well tissue culture cluster was coated for $4 \mathrm{~h}$ at $37^{\circ} \mathrm{C}$ with $50 \mu \mathrm{l} /$ well of $3 \mu \mathrm{g} / \mathrm{ml} \mathrm{P}$-selectin in DPBS, then washed and blocked as for E-selectin plates above.

Adherence assays. Peripheral blood was obtained by venipuncture from healthy donors and patients with leukocyte adhesion deficiency syndromes (LAD I patient [7] and LAD II patient [12]) after informed consent according to protocols approved by the Human Subjects Review Boards of the University of Washington and the Rambam Medical Center. The blood was collected in syringes containing heparin $(10 \mathrm{U} / \mathrm{ml})$ and the neutrophils were isolated as previously described (28). Isolated neutrophils were washed three times in PBS and resuspended to 2 $\times 10^{7} / \mathrm{ml}$ in PBS containing $5 \mathrm{mM}$ glucose, $0.7 \mathrm{mM} \mathrm{CaCl}_{2}$, and 0.7 $\mathrm{mM} \mathrm{MgCl}$ except where otherwise indicated.

Assay plates were washed twice in HBSSg/BSA and then incubated with $100 \mu \mathrm{l}$ of buffer containing antibodies at the concentrations indicated in the figure legends and/or PMA at $10^{-7} \mathrm{M}$ where indicated. Neutrophils $\left(5 \times 10^{5}\right.$ in $50 \mu \mathrm{l}$ of HBSSg per well) were added and allowed to settle for $5 \mathrm{~min}$ (activated HUVEC plates) or $10 \mathrm{~min}$ (purified E- or P-selectin plates). The plates were then washed three times by inverting and refilling with $200 \mu \mathrm{l}$ of HBSSg/BSA using a multichannel pipette. Neutrophil adherence was quantitated by spectrophotometric analysis of myeloperoxidase (29).

Neutrophil migration assays. Human umbilical vein endothelial cells were grown in Transwells ${ }^{\mathrm{TM}}$ (3- $\mu \mathrm{m}$ pore) (Costar Corp.) prepared with a thin coat of Matrigel (Collaborative Research, Inc., Waltham, MA). Neutrophils were labeled with $\mathrm{Na}{ }^{51} \mathrm{Cr}$-Chromate (NEN, Boston, MA) $1 \mu \mathrm{Ci} / 10^{6}$ cells at $37^{\circ} \mathrm{C}$ for $30 \mathrm{~min}$. Unincorporated ${ }^{51} \mathrm{Cr}$ was removed by three washes. Purified ${ }^{51} \mathrm{Cr}$-labeled patient and control neutrophils were pretreated with buffer or with CD18 mAb $60.3(20 \mu \mathrm{g} / \mathrm{ml})$ for 10 min at room temperature before addition to decanted wells. FMLP 
(Sigma Chemical Co.), $10^{-6} \mathrm{M}$, was placed in the lower chamber as chemoattractant. Migration across the HUVEC and polycarbonate membrane was assessed after $90 \mathrm{~min}$ at $37^{\circ} \mathrm{C}$ by harvesting medium and cells from the lower wells and counting ${ }^{51} \mathrm{Cr}$-cpm on a gamma radiation counter (Beckman Instruments, Inc., Fullerton, CA). Blood from the patient was brought to the United States for a further experiment and neutrophils were prepared as previously. To control for nonspecific effects of immunoglobulins, normal donor neutrophils were preincubated with mAb 60.3 or with isotype-matched neutrophil-binding $\mathrm{mAb}$ JP34-10 and tested for transmigration.

Neutrophil spreading. $50 \mu \mathrm{l}$ of PMA $\left(10^{-6} \mathrm{M}\right)$ in endotoxin-free $\mathrm{H}_{2} \mathrm{O}$ were dried on each of several glass coverslips. Normal donor and patient neutrophils treated with buffer or CD18 mAb (60.3) were plated on the dried PMA and incubated at $37^{\circ} \mathrm{C}$ for $15 \mathrm{~min}$. Coverslips were fixed with $3 \%$ glutaraldehyde in PBS at room temperature, washed with PBS, and stored in PBS until photographed in a light microscope and then processed for scanning electron microscopy. Coverslips were treated with $1 \%$ osmium tetroxide in $0.1 \mathrm{M}$ PBS ( $\mathrm{pH} 7.2-7.4$ ), washed twice in PBS, dehydrated through graded ethanol solutions to $100 \%$ ethanol and critical-point dried. Cells were mounted on scanning electron microscope studs, sputter-coated with gold-palladium for $2 \mathrm{~min}$ and scanned on a field emission microscope (JEOL U.S.A. Inc., Peabody, MA). Representative fields were photographed.

Statistics. Probability values were obtained using Student's $t$ test, two-tailed, with unequal variance using Excel (Microsoft Corp., Redmond, WA).

\section{Results}

Expression of cell adhesion molecules and surface markers on LAD II leukocytes. LAD II patient leukocytes were examined for their expression of surface markers associated with cellular adhesion functions. As previously reported (12), LAD II neutrophils were deficient in expression of the $\mathrm{Le}^{\mathrm{x}}$ (CD15) antigen (7C3 $\mathrm{mAb}$ ) and the SLe ${ }^{\mathrm{x}}$ (CD15s) antigen (CSLEX-1 mAb) (Table I and Fig. 1). We have extended this finding by demonstrating that neutrophils from both parents of this patient express normal levels of $\mathrm{Le}^{\mathrm{x}}$ and $\mathrm{Sle}^{\mathrm{x}}$ (Table I). In addition, peripheral blood mononuclear leukocytes of the LAD II patient were deficient in expression of SLe ${ }^{x}$ (Table I).

In contrast to SLe ${ }^{x}$ expression, both $\mathrm{LAD}$ II and parental neutrophils had normal levels of the integrin subunits CD11b (OKM-1 mAb) and CD18 (60.3 mAb). Patient neutrophils also expressed normal levels of CD43 (BS1 mAb), CD66 (Gran/ $10 \mathrm{mAb}$ ), CD16 (Leu 11b mAb), and CD45RO (UCHL-1 mAb) (Table I). Upon activation by PMA, LAD II neutrophils exhibited increased binding of CD11b (Fig. 1) and CD66 mAbs (Table I) and reduced binding of CD43 mAb (Table I), comparable to that seen with normal donor cells. Of particular interest was the normal level of L-selectin (CD62L; Leu $8 \mathrm{mAb}$ ) seen on LAD II neutrophils and the down-regulation of its expression induced by PMA activation, comparable to that observed with normal donor cells (Fig. 1).

Peripheral blood mononuclear cells from a LAD II patient expressed normal levels of the memory $T$ cell marker CD45RO (UCHL-1 mAb), but failed to bind HECA-452 mAb, a marker for skin-homing $\mathrm{T}$ lymphocytes also found on neutrophils (30, $31)$, that recognizes sialyl-Lewis $\mathrm{A}\left(\mathrm{SLe}^{\mathrm{a}}\right)$ as well as $\mathrm{SLe}^{\mathrm{x}}$ (22) (Table I).

Shape changes consistent with activation of neutrophils, demonstrated by decreases in $90^{\circ}$ light scatter and increases in forward light scatter, were seen in both control and patient cells in response to $30 \mathrm{~s}$ treatment with $10^{-7} \mathrm{M}$ FMLP at $37^{\circ} \mathrm{C}$. Control neutrophil $90^{\circ}$ light scatter mean channel number de- creased from 172 to 155 . Similarly, patient neutrophil $90^{\circ}$ light scatter mean channel number decreased from 170 to 138 . Forward light scatter increased somewhat in both cases (control: mean channel 118 to 122 ; patient: mean channel 103 to 119 ).

LAD II neutrophils demonstrate defects in binding to purified selectins. Neutrophils isolated from peripheral blood of a LAD II patient and a normal control were examined for their ability to bind to purified platelet-derived P-selectin and to purified recombinant E-selectin. As seen in Fig. 2, normal donor neutrophils bound to P-selectin in the presence but not in the absence of divalent cations. This adherence was inhibited by anti-SLe $^{\mathrm{x}} \mathrm{mAb}(\mathrm{A} 490=1.05$ vs $0.78, P<0.05)$. LAD II neutrophils did not bind to P-selectin in the presence or in the absence of divalent cations (Fig. 2).

Similarly, normal donor neutrophils bound to recombinant E-selectin in the presence but not in the absence of divalent cations (Fig. 2). This adherence was inhibited by anti-SLe ${ }^{x}$ $\mathrm{mAb}(\mathrm{A} 490=0.88$ vs $0.42, P<0.01)$. Patient neutrophils bound weakly to recombinant E-selectin in the presence, but not in the absence of divalent cations (Fig. 2). This small amount of adherence was not inhibited significantly by SLe ${ }^{\mathrm{x}}$ $\mathrm{mAb}(\mathrm{A} 490=0.16$ vs $0.12, P>0.1)$.

$L A D$ II neutrophils bind minimally to TNF-or to histamineactivated HUVEC but can be activated by PMA to adhere to $H U V E C$. To determine the effect of SLe ${ }^{x}$ deficiency on neutrophil binding in the presence of receptors for the $\beta_{2}$ integrins LFA-1 and Mac-1, we examined neutrophil adherence to TNFand to histamine-activated HUVEC. Normal donor neutrophils bound significantly to TNF-activated HUVEC (Fig. 3) and to histamine-activated HUVEC (Fig. 4). In each case the binding was partially blocked by addition of CD18 mAb (60.3) or of anti-SLe ${ }^{\mathrm{x}}$ mAb (CSLEX-1), and there was an additive effect when the two mAbs were used in combination. Isotypematched, neutrophil-binding control mAbs (JP34-10 for 60.3 and CDw17 for CSLEX-1) did not inhibit binding of control neutrophils $(P>0.1$ in each case $)$. Complete blocking of adhesion was achieved when higher concentrations of CSLEX-1 $\mathrm{mAb}$ were used $(10 \mu \mathrm{g} / \mathrm{ml})$; however, some agglutination of neutrophils occurred at this concentration of $\mathrm{mAb}$. These results indicate that adherence of normal neutrophils to activated endothelial cells involves both SLe ${ }^{x}$ binding to E- and P-selectins and $\beta_{2}$ integrins binding to their receptors.

LAD I neutrophils also bound well to histamine-activated HUVEC. As expected, LAD I neutrophil adherence was not inhibited by CD18 mAb but was inhibited by anti-SLe ${ }^{x} \mathrm{mAb}$ (Fig. 4). In these static assays LAD II neutrophils bound minimally to TNF-activated HUVEC (Fig. 3 ) or to histamine-activated HUVEC (Fig. 4). In both cases this small amount of binding was completely blocked by CD18 mAb but not by anti$\mathrm{SLe}^{\mathrm{x}} \mathrm{mAb}$.

Phorbol myristate acetate treatment of LAD II neutrophils induced marked adhesion to unactivated endothelium as it did for normal donor neutrophils (Fig. 4). The PMA-induced binding of control and LAD II neutrophils was completely blocked by $\mathrm{CD} 18 \mathrm{mAb}$ (Fig. 4). In a separate experiment control isotype-matched $\mathrm{mAb}$ did not inhibit PMA-induced adherence of control neutrophils ( $\mathrm{A} 490=2.16$ vs $2.19, P>0.1$ ) while $\mathrm{CD} 18$ mAb was very effective (A490 $=2.16$ vs $0.23, P<0.01, n$ $=5$ ). LAD I neutrophils increased adherence slightly with PMA treatment, but CD18 mAb had no effect on this small amount of adherence (Fig. 4).

LAD II neutrophils migrate through endothelial monolayers 
Table I. Flow Cytometry of Peripheral Blood Leukocytes (Mean Channel Number)

\begin{tabular}{|c|c|c|c|c|c|c|c|c|}
\hline \multirow[b]{2}{*}{ Antibody } & \multicolumn{2}{|c|}{ Control } & \multicolumn{2}{|c|}{ LADII } & \multicolumn{2}{|c|}{ Mother } & \multicolumn{2}{|c|}{ Father } \\
\hline & Basal & PMA & Basal & PMA & Basal & PMA & Basal & PMA \\
\hline \multicolumn{9}{|l|}{ Experiment 1 (neutrophils) } \\
\hline MIg* & 9 & 24 & 5 & 9 & 7 & 17 & 11 & 16 \\
\hline CSLEX-1 $\left(\right.$ SLe $\left.^{x}\right)$ & 167 & 137 & 5 & 7 & 155 & 95 & 144 & 106 \\
\hline $7 C 3\left(\operatorname{Le}^{x}\right)$ & 56 & 56 & 5 & 8 & 41 & 33 & 34 & 31 \\
\hline Leu 8 (L-selectin) & 124 & 24 & 126 & 9 & $\mathrm{nd}^{\ddagger}$ & nd & nd & nd \\
\hline OKM-1 (CD11b) & 105 & 118 & 85 & 141 & 109 & 112 & 97 & 128 \\
\hline $60.3(\mathrm{CD} 18)$ & 129 & 119 & 121 & 161 & 133 & 126 & 124 & 151 \\
\hline BS1 (CD43) & 130 & 55 & 126 & 47 & 135 & 27 & nd & 43 \\
\hline Gran10 (CD66) & 65 & 114 & 77 & 143 & nd & nd & nd & nd \\
\hline \multicolumn{9}{|l|}{ Experiment 2 (neutrophils) } \\
\hline MIg & 0 & nd & 10 & nd & & & & \\
\hline CSLEX-1 $\left(\right.$ SLe $\left.^{x}\right)$ & 165 & nd & 3 & nd & & & & \\
\hline Leu 11b (CD16) & 113 & nd & 87 & nd & & & & \\
\hline UCHL-1 (CD45RO) & 97 & nd & 118 & nd & & & & \\
\hline Anti-rat control & 39 & nd & 67 & nd & & & & \\
\hline HECA $452\left(\right.$ SLe $\left.^{\mathrm{a}} / \mathrm{SLe}^{\mathrm{x}}\right)$ & 199 & nd & 66 & nd & & & & \\
\hline \multicolumn{9}{|c|}{ Experiment 2 (mononuclear cells) } \\
\hline MIg & 0 & nd & 5 & nd & & & & \\
\hline CSLEX-1 $\left(\right.$ Sle $\left.^{x}\right)$ & 56 & nd & 3 & nd & & & & \\
\hline Leu 11b (CD16) & 8 & nd & 5 & nd & & & & \\
\hline UCHL-1 (CD45RO) & 62 & nd & 27 & nd & & & & \\
\hline Anti-rat control & 29 & nd & 27 & nd & & & & \\
\hline HECA $452\left(\right.$ SLe $\left.^{a} / S_{L} e^{x}\right)$ & 50 & nd & 29 & nd & & & & \\
\hline
\end{tabular}

* MIg, mouse immunoglobulin; ${ }^{\ddagger}$ nd, not determined.

in response to FMLP. LAD II patients show impaired emigration of neutrophils in vivo (32). Since PMA treatment of LAD II neutrophils induced adherence to endothelium in vitro (Fig. 4), it seemed likely that the impairment in emigration observed in vivo resulted from the loss of the selectin-mediated phase of neutrophil adherence. To test this hypothesis further, the ability of LAD II neutrophils to respond to FMLP by transmigration across an endothelial monolayer was examined. As can be seen in Fig. 5, LAD II neutrophils migrated toward the chemoattractant. This response was dependent upon CD18 as demonstrated by the complete inhibition of transmigration in the presence of the CD18 mAb 60.3. Statistical analysis of the data showed a significant difference for both normal donor and patient between basal vs FMLP-stimulated transmigration, $(P<0.05)$; and between CD18 mAb-treated vs untreated neutrophil transmigration to FMLP, $(P<0.01)$; with no significant difference between patient transmigration to FMLP and that of normal donor. When patient blood was carried from Israel to the United States and neutrophil transendothelial migration in response to FMLP was again compared to transmigration to control medium, similar results were obtained (Fig. 5). Isotype-matched control antibody did not inhibit transmigration of normal neutrophils toward FMLP (inhibition with CD13 mAb $-8 \pm 4 \%$ versus $90 \pm 3 \%$ inhibition with $\mathrm{CD} 18 \mathrm{mAb}$, mean \pm SD of six replicates).

Neutrophil spreading. Normal donor and LAD II neutrophils spread on PMA-coated glass coverslips (Fig. 6). In contrast, LAD I neutrophils (Fig. 6) and normal donor and LAD
II neutrophils that had been treated with the CD18 mAb 60.3 (data not shown) failed to spread.

\section{Discussion}

LAD II is a newly described congenital disorder of neutrophil adhesion. Like the classic leukocyte adhesion deficiency syndrome, now designated type 1 (LAD I), LAD II is characterized by neutrophilia, recurrent bacterial infections, decreased neutrophil motility and adhesion in vitro (12), and defective neutrophil emigration in vivo as assessed by skin chamber and skin window (32). In contrast to LAD I cells, neutrophils from the two known patients with LAD II syndrome were shown to express normal levels of CD11/CD18. Instead, LAD II cells were found to be deficient in SLe ${ }^{\mathrm{x}}$, a fucose-containing carbohydrate moiety, and were unable to bind to E-selectin expressed on interleukin- $\beta$-activated human umbilical vein endothelial cells. These results suggested that the adhesion deficiency in these patients was caused by a lack of carbohydrate ligand, $\mathrm{SLe}^{\mathrm{x}}$, which is required for selectin-mediated neutrophil adhesion to endothelial cells $(33-35)$. In this report, we further characterize neutrophil adhesion in LAD II.

Consistent with a defect in fucose metabolism, neutrophils from the LAD II patient failed to express the fucose-containing $\mathrm{Le}^{\mathrm{x}}, \mathrm{SLe}^{\mathrm{x}}$, and HECA-452 antigens. Interestingly, although presumably heterozygous for the genetic defect $(12,36)$, parental neutrophils exhibited normal levels of SLe ${ }^{x}$. Patient neutrophils expressed normal levels of several adhesion protein anti- 

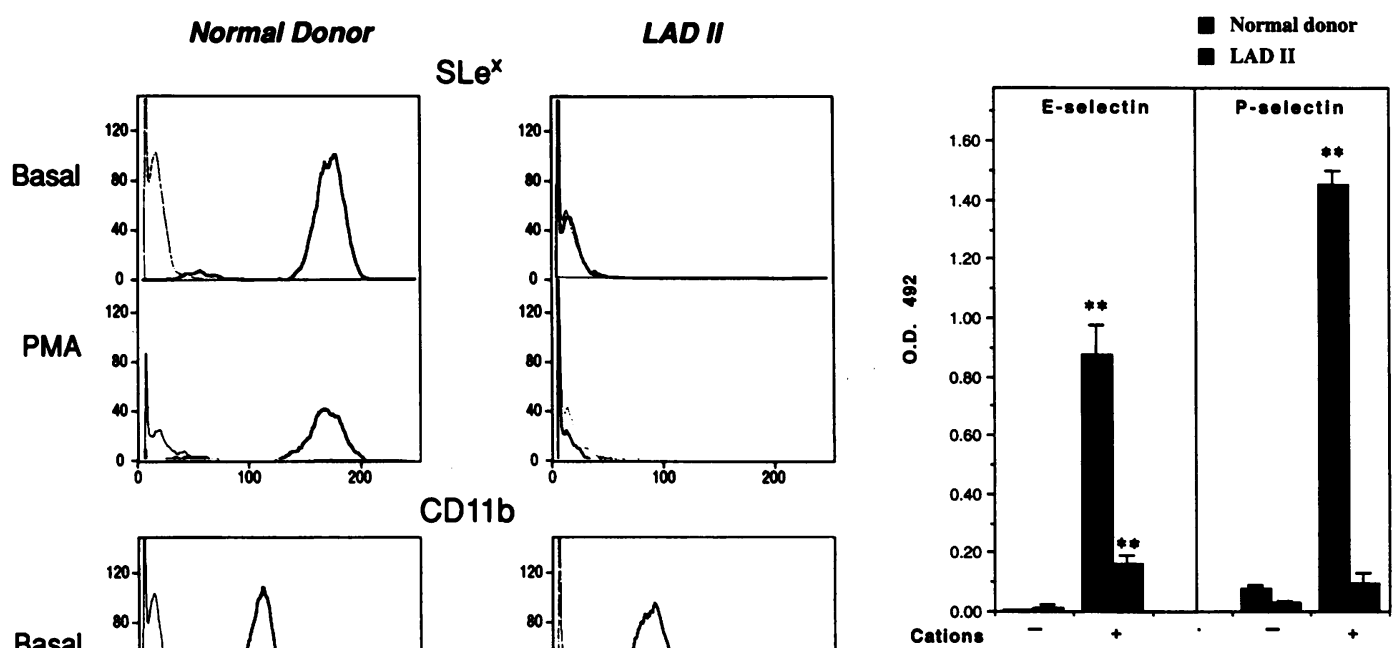

Figure 2. Neutrophil adherence to purified Eand P-selectins. Purified neutrophils from a normal donor or the LAD II patient were incubated on assay plates coated with purified recombinant human E-selectin or purified human plateletderived P-selectin for 5 $\mathrm{min}$ and the plates were then washed. To test the effect of divalent cations on neutrophil adhesion, the assay was performed in the presence or absence of $0.7 \mathrm{mM} \mathrm{CaCl}{ }_{2}$ and $0.7 \mathrm{mM} \mathrm{MgCl}_{2}$. Ad-

Basal

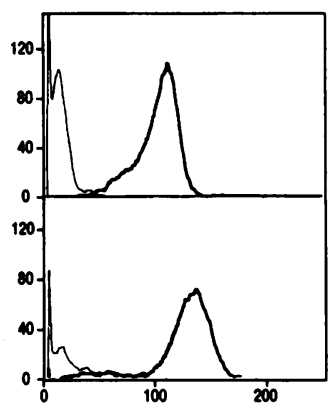

L-selectin

Basal

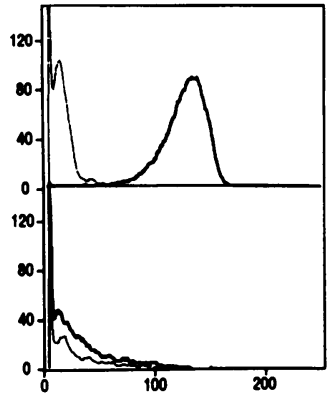

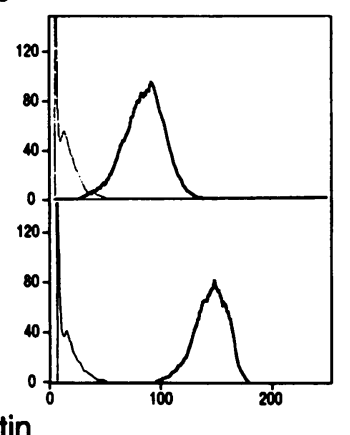

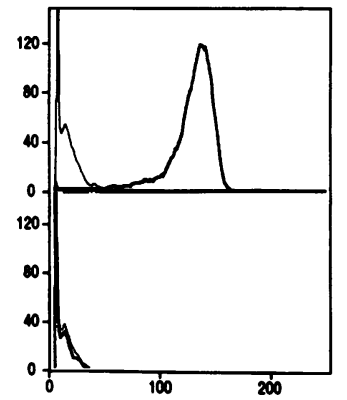

Figure 1. Flow cytometry of neutrophils. Binding of mAbs to unstimulated and PMA-activated LAD II patient and normal donor leukocytes was assessed by indirect immunofluorescence as described in Methods. Cell number is recorded on the ordinate and fluorescence channel number on the abscissa. Mixed mouse immunoglobulins $(M I g)$ were used to control for nonspecific binding.

gens including L-selectin and the $\beta_{2}$ integrin subunits CD11b and CD18. The finding that patient cells exhibited normal levels of L-selectin is of considerable interest in view of the fact that $\mathrm{L}$-selectin on neutrophils has been shown to present SLe ${ }^{\mathrm{x}}$ for recognition by $\mathrm{E}$ - and P-selectins (37), and this function is absent in LAD II cells. L-selectin has also been demonstrated to recognize a structure induced on cytokine-activated endothelium in vitro (38), and on inflamed endothelium in the systemic microcirculation in vivo (39). Studies by von Andrian et al. (40) demonstrated that purified, fluorescein-labeled LAD II neutrophils show an $80 \%$ reduction in rolling compared to normal donor or LAD I cells. The residual rolling observed with patient cells in this model may be due to neutrophil L-selectin interaction with a nonfucose-containing carbohydrate ligand on the inflamed rabbit endothelium.

Because of the small volumes of blood that could be withdrawn from the child, only limited flow cytometry studies were performed on mononuclear leukocytes. Patient cells expressed herence was quantitated by spectrophotometric analysis of the neutrophil-specific enzyme myeloperoxidase as described in Methods. $* * P$ $<0.01$, for adherence with cations compared to adherence without cations.

levels of the memory $\mathrm{T}$ cell marker CD45RO roughly comparable to normal adult controls, but failed to bind both the CSLEX$1 \mathrm{mAb}$ that recognizes $\mathrm{SLe}^{\mathrm{x}}$ and the HECA-452 mAb that recognizes $\mathrm{SLe}^{\mathrm{a}}$ as well as $\mathrm{SLe}^{\mathrm{x}}(22)$. SLe ${ }^{\mathrm{x}}$ is expressed on natural killer cells $(41,42)$, a subset of memory $T$ cells, and activated

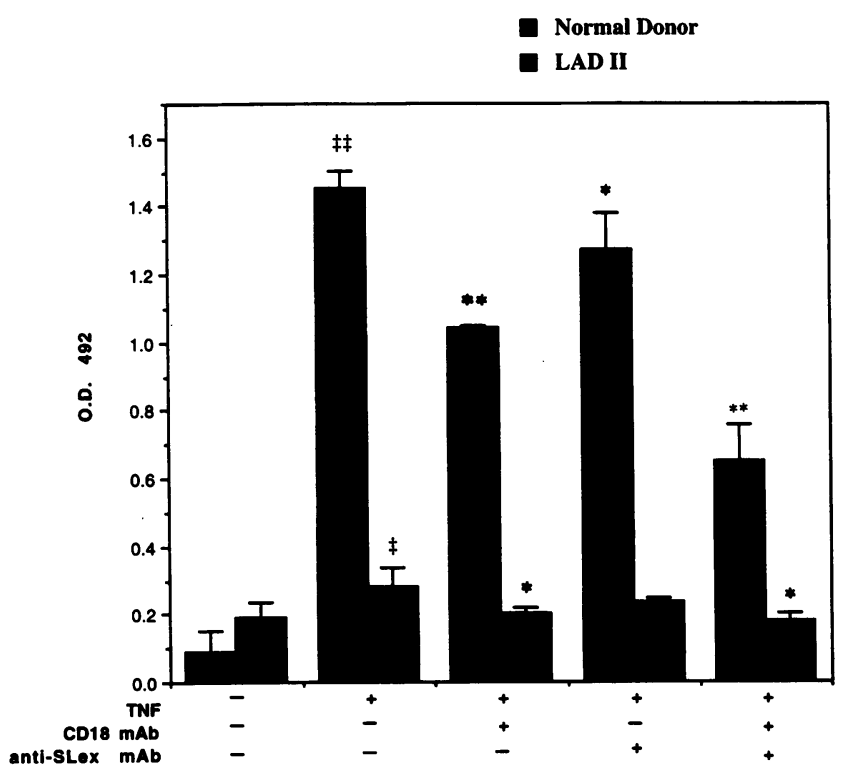

Figure 3. Neutrophil adherence to TNF-activated HUVEC. Purified neutrophils from a normal donor or the LAD II patient were incubated for $5 \mathrm{~min}$ on HUVEC monolayers which had been activated for $4 \mathrm{~h}$ with recombinant human TNF $(2 \mathrm{ng} / \mathrm{ml})$ or treated with control medium. In some wells, the CD18 mAb (60.3) $(20 \mu \mathrm{g} / \mathrm{ml})$ or anti-SLe ${ }^{x} \mathrm{mAb}$ $($ CSLEX-1) $(6 \mu \mathrm{g} / \mathrm{ml})$ was present in the wells during the neutrophil incubation. The plates were washed and adherence was quantitated by spectrophotometric analysis of the neutrophil-specific enzyme myeloperoxidase as described in Methods. ${ }^{*} P<0.05$ or ${ }^{* *} P<0.01$, for adherence of $\mathrm{mAb}$-treated neutrophils compared to untreated neutrophils to TNF-activated HUVEC. ${ }^{\ddagger} P<0.05$ or ${ }^{\ddagger \ddagger} P<0.01$, for adherence to TNF-activated HUVEC compared to basal adherence. 


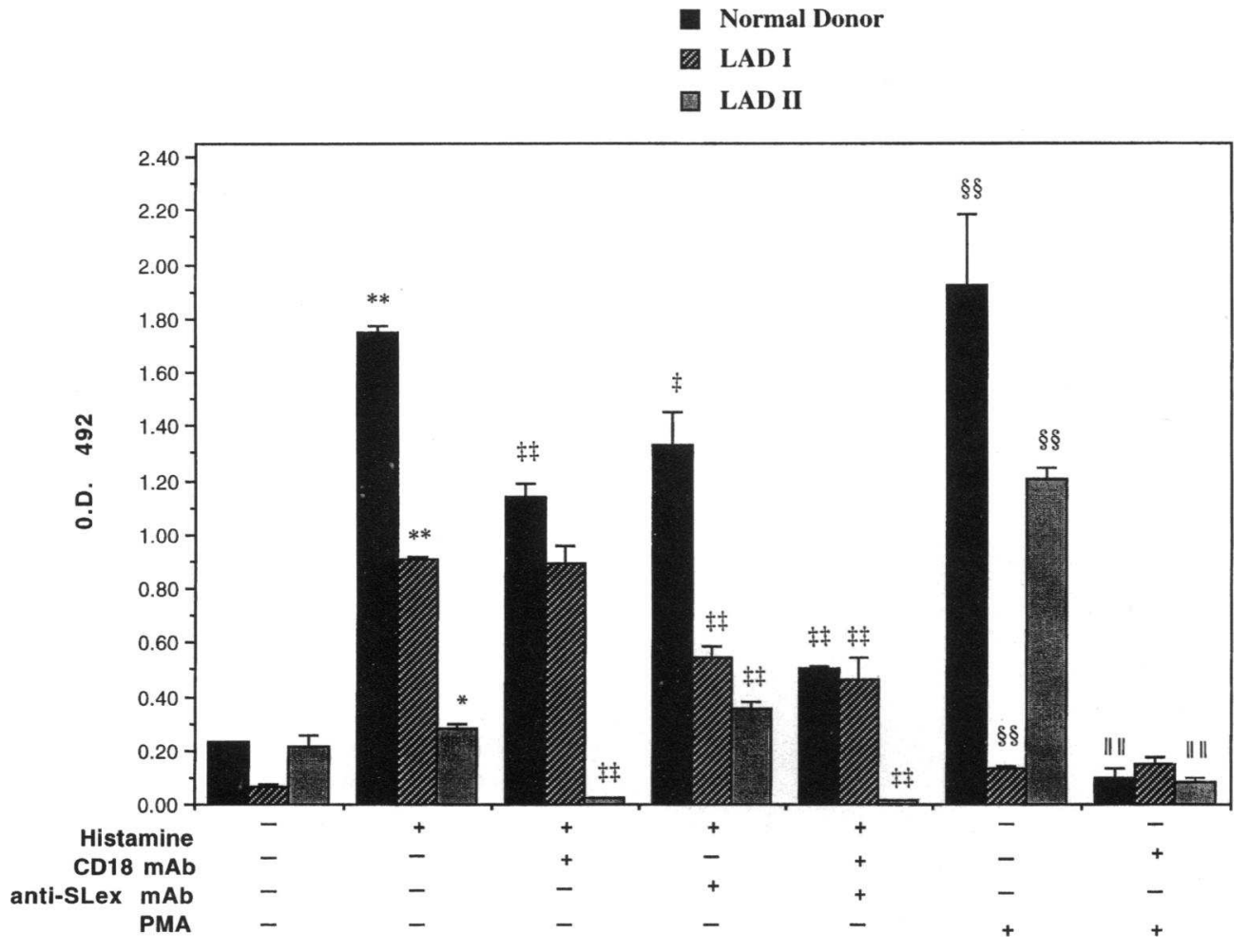

Figure 4. Neutrophil adherence to histamine-activated HUVEC. Purified neutrophils from a normal donor, the LAD I patient or the LAD II patient were incubated for 5 min on primary HUVEC monolayers that had been activated for 5 min with histamine at $\left(5 \times 10^{-5}\right.$ M) or treated with control medium. In some wells, the CD18 $\mathrm{mAb}(60.3)(20 \mu \mathrm{g} / \mathrm{ml})$, anti$\mathrm{SLe}^{\mathrm{x}}(\mathrm{CSLEX}-1) \mathrm{mAb}(6 \mu \mathrm{g} / \mathrm{ml})$ and/or PMA $\left(10^{-7} \mathrm{M}\right)$ were present in the wells during the neutrophil incubation. The plates were washed three times and adherence was quantitated by spectrophotometric analysis of the neutrophilspecific enzyme myeloperoxidase as described in Methods. ${ }^{*} P$ $<0.05$ or $* * P<0.01$, for neutrophil adherence to to histamine-activated HUVEC compared to basal adherence. ${ }^{\ddagger} P<0.05$ or ${ }^{\ddagger \ddagger} P$ $<0.01$, for mAb-treated neutrophil adherence compared to untreated neutrophil adherence to histamine-activated HUVEC. ${ }^{\S \S} P$ $<0.01$, for PMA-induced adherence compared to basal adherence. IIII $P<0.01$, for mAb-treated neutrophil compared to untreated neutrophil adherence induced by PMA.

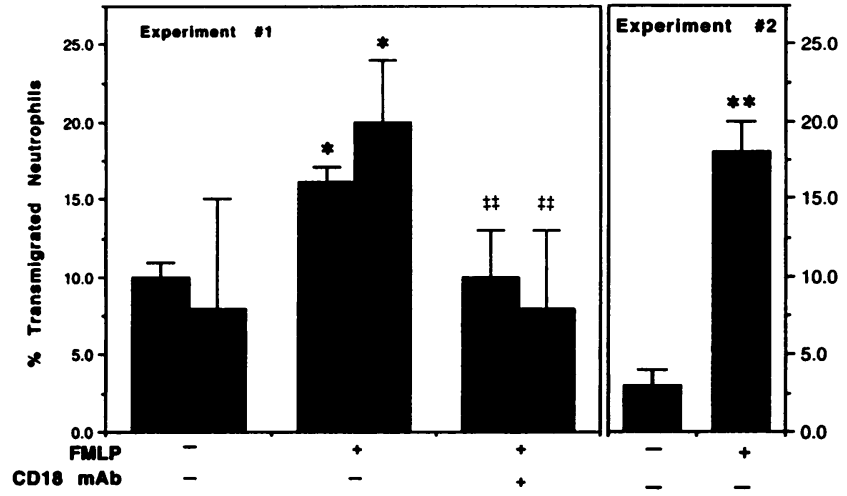

Figure 5. Neutrophil transendothelial migration. ${ }^{51} \mathrm{Cr}$-labeled neutrophils were incubated on HUVEC monolayers grown to confluence in transwells. In experiment 1, neutrophils from a normal donor or a LAD II patient were either pretreated with medium alone or medium containing the CD18 mAb $(60.3)(20 \mu \mathrm{g} / \mathrm{ml})$. In experiment 2 , only untreated LAD II cells were tested. In both experiments f MLP $\left(10^{-7} \mathrm{M}\right)$ was placed in the lower chamber of the indicated samples to act as chemoattractant. Migration was assessed following a 90-min incubation at $37^{\circ} \mathrm{C}$ by determining ${ }^{51} \mathrm{Cr}$-cpm present in the lower well as described in Methods. ${ }^{*} P<0.05$ or $* * P<0.01$, for transmigration to FMLP compared to basal transmigration. ${ }^{\ddagger \ddagger} P<0.01$, for mAb-treated neutrophil transmigration compared to untreated neutrophil transmigration. peripheral blood T and B cells (43). Although not directly tested, binding of these LAD II mononuclear cells to P- or Eselectin would likely be decreased, and emigration in vivo to sites of immune reaction may consequently be reduced. Similarly, monocyte emigration would also be expected to be affected as peripheral monocytes express $\operatorname{SLe}^{\mathrm{x}}(44)$, and bind to $\mathrm{E}$ - and P-selectins $(45,46)$. Indeed, skin window studies in this patient demonstrate a marked reduction in monocyte emigration (32). Picker et al. (31) reported that the HECA-452 mAb identified skin-homing memory $\mathrm{T}$ cells that bind to E-selectin. The traffic of these particular memory $\mathrm{T}$ cells to immune-reactive dermal sites would also likely be impaired in LAD II syndrome.

In a previous report (12), LAD II neutrophils were shown not to bind to E-selectin induced on HUVEC monolayers by interleukin- $1 \beta$. In the current study, we examined neutrophil adherence to TNF-activated HUVEC monolayers under static assay conditions, and found that LAD II neutrophils bound minimally to cytokine-activated HUVEC. These results with Eselectin expressed on HUVEC were confirmed by demonstrating that LAD II neutrophils showed a marked reduction in calcium-dependent binding to recombinant E-selectin.

The marked reduction in LAD II neutrophil adhesion to cytokine- or histamine-treated HUVEC monolayers or to purified selectins suggests that efficient binding requires the interaction of the lectin domain of the selectin receptor with a fucosecontaining glycoconjugate ligand(s) on the neutrophil. Thus, potential selectin receptor interactions with sulfatides which have been previously described (47) are not alone sufficient for adhesion under these static assay conditions. The high affinity 

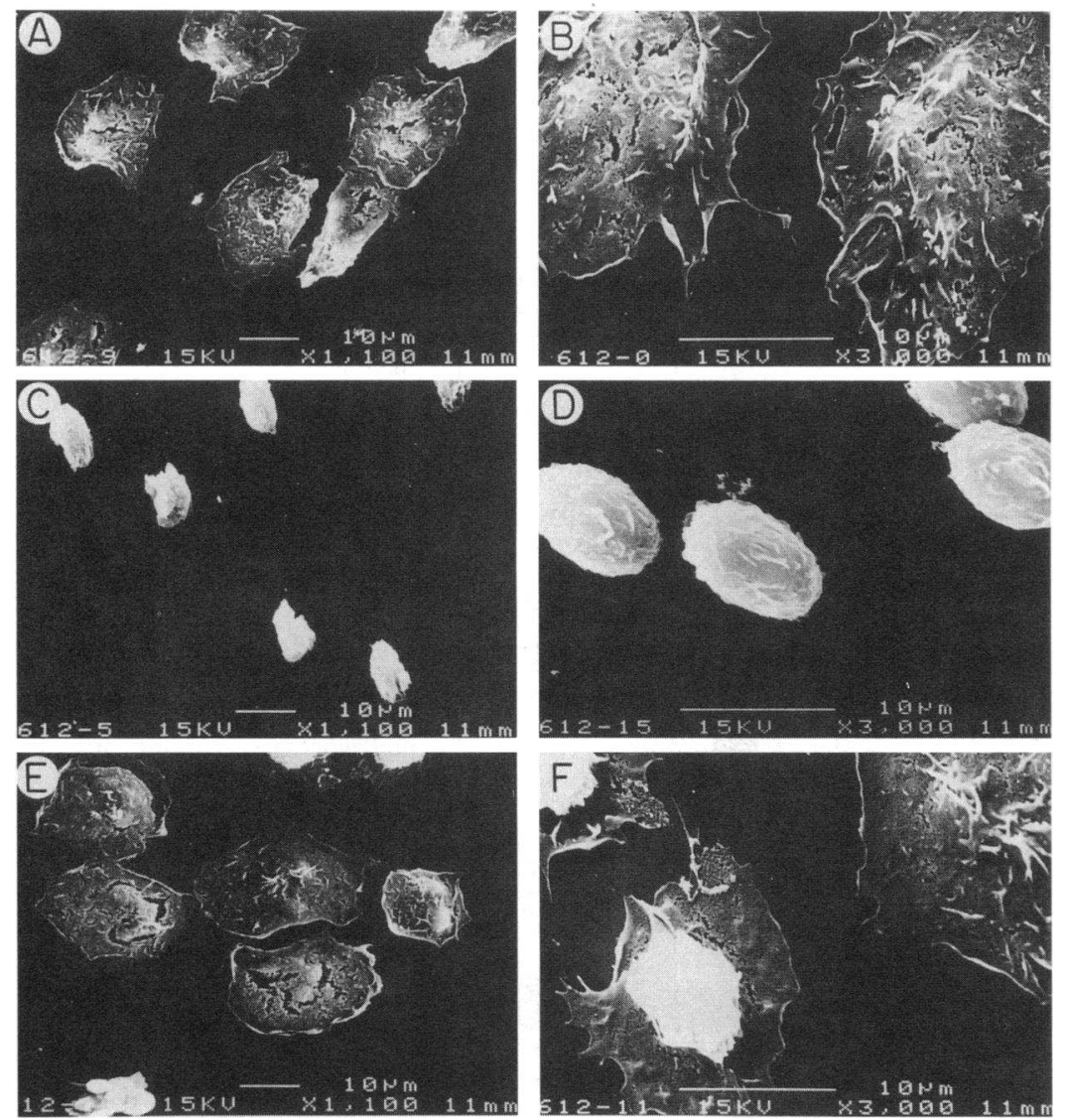

Figure 6. Neutrophil spreading. Normal donor ( $A$ and $B)$, LAD I ( $C$ and $D$ ), and LAD II ( $E$ and $F$ ) neutrophils adherent to PMA-coated glass coverslips. Representative fields from scanning electron microscopy are shown (A, C, and $\mathrm{E}, \times 1,000 ; \mathrm{B}, \mathrm{D}$, and $\mathrm{F}, \times 3,000)$. glycoprotein ligands identified for P- $(48,49)$ and E- $(50)$ selectins on neutrophils presumably function to present $\mathrm{SLe}^{\mathrm{x}}$ and/or other sialylated and fucosylated ligands to the receptors.

Etzioni et al. (12) also demonstrated a marked impairment of neutrophil chemotaxis in an under-agarose assay. This finding was not readily explained by a biochemical deficiency in SLe ${ }^{\mathrm{x}}$, and suggested a more global defect in cell activation or adhesion. Using flow cytometry, we have demonstrated that the patient neutrophils could be normally activated as assessed by: (a) up-regulation of CD66, CD18, and CD11b, and down-regulation of L-selectin and CD43 in response to phorbol ester; and $(b)$ changes in $90^{\circ}$ and forward light scatter as an indicator of shape change in response to FMLP. These results are consistent with previous demonstration of normal chemiluminescence of LAD II neutrophils in response to serum-opsonized zymosan and phorbol ester $(12,36)$.

Since CD11b has been shown to express $\operatorname{Le}^{x}(51)$, we considered the possibility that the defect in fucose metabolism somehow affected CD11/CD18 function. CD11/CD18 adhesive function was tested directly in several static adhesion assays. When activated by phorbol ester, LAD II neutrophils showed a marked increase in adhesion to HUVEC, comparable to that observed with normal donor neutrophils. Patient cells also migrated across HUVEC monolayers in response to FMLP, a CD11/CD18-dependent function (7). This latter result in vitro is in keeping with in vivo studies of von Andrian et al. (40). These investigators examined the interaction of LAD II neutrophils with endothelium in inflamed rabbit mesenteric vessels, and found that LAD II neutrophils were able to emigrate from the vessel lumen to tissue when flow (i.e., shear force) was reduced. We also examined $\mathrm{CD} 11 / \mathrm{CD} 18$-mediated neutrophil spreading on phorbol ester-treated glass cover slips. The LAD I neutrophils were polarized, but failed to flatten and spread. Normal cells and the majority of LAD II cells were flattened and extensively spread with pseudopod formation. Interestingly, a small percentage of the LAD II cells exhibited an intermediate appearance with some pseudopod formation, but retaining a more spherical shape. However, from the assays performed in this study, the defect in under-agarose chemotaxis of LAD II cells cannot be ascribed to CD11/CD18 dysfunction.

Homotypic aggregation of LAD II cells was not directly tested in this study, but it is of interest that L-selectin as well as CD18 has recently been demonstrated to participate in this adhesive interaction (52). It is possible that $\mathrm{L}$-selectin recognition of an SLe ${ }^{\mathrm{x}}$-like fucose-containing ligand is involved in the initial stabilization of the cell-cell aggregates, before adhesion strengthening mediated by the interaction of the $\beta_{2}$ integrins with its as yet unidentified ligand (53).

Our studies show a severe reduction in binding of LAD II neutrophils to E- and P-selectins, a finding consistent with the marked impairment in neutrophil emigration to skin windows or chambers reported in the LAD II patient (32) and to inflamed peritoneum observed in E-selectin null mice treated with an anti-P-selectin mAb (54). Importantly, although the LAD II patients have a severe defect in the function of two selectin pathways, their clinical course to date has been relatively mild when compared to that of patients with complete $\beta_{2}$ integrin deficiency. Both syndromes manifest themselves in the first few days of life, but with different symptoms. In LAD I delayed separation of the umbilical cord with omphalitis is typical. In 
LAD II, pneumonia with very marked neutrophilia in the first week of life was observed in both patients. During infancy and early childhood recurrent pneumonia and otitis media occurred in the two LAD II patients. These were not life-threatening events and were usually treated in the outpatient clinics. Several episodes of mild to moderate skin infections without obvious pus were also observed. In the last four years the frequency of infections has decreased and the children are off prophylactic antibiotics, but marked neutrophilia persists. Overall, the infections in LAD II appear to be comparable to the moderate rather than the severe phenotype of LAD I. We speculate that the ability of LAD II neutrophils to adhere and transmigrate via $\beta_{2}$ integrins under conditions of reduced shear forces (40) may allow some neutrophils to emigrate at sites of severe inflammation where flow may be impaired, thereby allowing some level of neutrophil defense against bacterial infection.

In summary, this report has provided further characterization of neutrophil function in the newly described LAD II syndrome. The major findings of our studies are: $(a) \mathrm{SLe}^{\mathrm{x}}$ and other fucose-containing antigens are absent on both neutrophils and mononuclear leukocytes; $(b)$ there is a marked defect in neutrophil binding to P-selectin as well as to E-selectin; $(c)$ neutrophil surface antigens modulate normally after activation; and $(d)$ CD11/CD18 adhesive functions are intact. Studies of leukocyte function in LAD I syndrome have proven invaluable in defining the role of $\beta_{2}$ integrin receptors in leukocyte-endothelial interactions, and it is anticipated that similar insights into selectin receptor biology will be gained from further careful investigation of the LAD II syndrome.

\section{Acknowledgments}

The authors would like to thank Tom McDonald for performing the scanning electron microscopy and William Way for technical assistance.

This study was supported by a grant from Cytel Corporation, San Diego, CA (J. M. Harlan).

\section{References}

1. Harlan, J. M., R. K. Winn, N. B. Vedder, C. M. Doerschuk, and C. L. Rice. 1992. In vivo models of leukocyte adherence to endothelium. In Adhesion its role in inflammatory disease. J. M. Harlan and D. Y. Liu, editors. Freeman Press, New York. 117-150.

2. Atherton, A., and G. V. R. Born. 1972. Quantitative investigations of the adhesiveness of circulating polymorphonuclear leukocytes to blood vessel walls. J. Physiol. 222:447-474.

3. Anderson, D. C., and T. A. Springer. 1987. Leukocyte adhesion deficiency: an inherited defect in the Mac-1, LFA-1 and p150/95 glycoproteins. Annu. Rev. Med. 38:175-194.

4. Anderson, D. C., C. W. Smith, and T. A. Springer. 1989. Leukocyte adhesion deficiency and other disorders of leukocyte motility. In The Metabolic Basis of Inherited Disease, 6th edition. C. R. Scriver, A. L. Beaudet, W. S. Sly, and D. Valle, editors. McGraw Hill Inc., New York. 2751-2777.

5. Price, T. H., P. G. Beatty, and S. R. Corpuz. 1987. In vivo inhibition of neutrophil function in the rabbit using monoclonal antibody to CD18. J. Immunol. 139:4174-4177.

6. Arfors, K.-E., C. Lundberg, L. Lindbom, K. Lundberg, P. G. Beatty, and J. M. Harlan. 1987. A monoclonal antibody to the membrane glycoprotein complex CD18 inhibits polymorphonuclear leukocyte accumulation and plasma leakage in vivo. Blood. 69:338-340.

7. Harlan, J. M., P. D. Killen, F. M. Senecal, B. R. Schwartz, E. K. Yee R. F. Taylor, P. G. Beatty, T. H. Price, and H. D. Ochs. 1985. The role of neutrophil membrane glycoprotein GP-150 in neutrophil adherence to endothelium in vitro. Blood. 66:167-178.

8. Smith, C. W., S. D. Marlin, R. Rothlein, C. Toman, and D. C. Anderson 1989. Cooperative interactions of LFA-1 and Mac-1 with intercellular adhesion molecule-1 in facilitating adherence and transendothelial migration of human neutrophils in vitro. J. Clin. Invest. 83:2008-2017.

9. Lawrence, M. B., C. W., Smith, S. G. Eskin, and L. V. McIntire. 1990.
Effect of venous shear stress on CD18-mediated neutrophil adhesion to cultured endothelium. Blood. 75:227-237.

10. Carlos, T. M., and J. M. Harlan. 1994. Leukocyte-endothelial adhesion molecules. Blood. 84:2068-2101.

11. Springer, T. A. 1994. Traffic signals for lymphocyte recirculation and leukocyte emigration: the multistep paradigm. Cell. 76:301-314.

12. Etzioni, A., M. Frydman, S. Pollack, I. Avidor, M. L. Phillips, J. C. Paulson, and R. Gershoni-Baruch. 1992. Recurrent severe infections caused by a novel leukocyte adhesion deficiency. N. Engl. J. Med. 327:1789-1792

13. Polley, M. J., M. L. Phillips, E. Wayner, E. Nudelman, A. K. Singhal, S-I. Hakomori, and J. C. Paulson. 1991. CD62 and endothelial cell-leukocyte adhesion molecule 1 (ELAM-1) recognize the same carbohydrate ligand, sialyl-Lewis $\mathrm{X}$. Proc. Natl. Acad. Sci. USA. 88:6224-6228.

14. Berg, E. L., J. Magnani, R. A. Warnock, M. K. Robinson, and E. C. Butcher. 1992. Comparison of L-selectin and E-selectin ligand specificities: The L-selectin can bind the E-selectin ligands Sialyl Le ${ }^{\mathrm{x}}$ and Sialyl Le $\mathrm{L}^{\mathrm{a}}$. Biochem. Biophys. Res. Commun. 184:1048-1055.

15. Foxall, C., S. R. Watson, D. Dowbenko, C. Fennie, L. A. Lasky, M. Kiso, A. Hasegawa, D. Asa, and B. K. Brandley. 1992. The three members of the selectin receptor family recognize a common carbohydrate epitope, the sialyl lewis X oligosaccharide. J. Cell Biol. 117:895-902.

16. Mulligan, M. S., M. J. Polley, R. J. Bayer, M. F. Nunn, J. C. Paulson, and P. A. Ward. 1992. Neutrophil-dependent acute lung injury. Requirement for P-selectin (GMP-140). J. Clin. Invest. 90:1600-1607.

17. Fukushima, K., M. Hirota, P. I. Terasaki, A. Wakisaka, H. Togashi, D. Chia, N. Suyama, Y. Fukushi, E. Nudelman, and S.-I. Hakomori. 1984. Characterization of sialosylated Lewis ${ }^{x}$ as a new tumor associated antigen. Cancer Res. 44:5279-5285.

18. Hickstein, D. D., R. M. Locksley, P. G. Beatty, A. Smith, D. M. Stone, and R. K. Root. 1986. Monoclonal antibodies binding to the human neutrophil C3bi receptor have disparate functional effects. Blood. 67:1054-1062.

19. Kuijpers, T. W., M. Hoogerwerf, K. C. Kuijpers, B. R. Schwartz, and J. M. Harlan. 1992. Cross-linking of sialophorin (CD43) induces neutrophil aggregation in a CD18-dependent and a CD18-independent way. J. Immunol. 149:9981003.

20. Wailis, W. J., D. D. Hickstein, B. R. Schwartz, C. H. June, H. D. Ochs, P. G. Beatty, S. J. Klebanoff, and J. M. Harlan. 1986. Monoclonal antibodydefined functional epitopes on the adhesion-promoting glycoprotein complex (CDw18) of human neutrophils. Blood. 67:1007-1013.

21. Smith, S. H., M. H. Brown, D. Rowe, R. E. Callard, and P. C. L. Beverley. 1986. Functional subsets of human helper-inducer cells defined by a new monoclonal antibody UCHL1. Immunology. 58:63-70.

22. Berg, E. L., M. K. Robinson, O. Mansson, E. C. Butcher, and J. L. Magnani. 1991. A carbohydrate domain common to both sialyl $\mathrm{Le}^{\mathrm{a}}$ and sialyl $\mathrm{Le}^{\mathrm{x}}$ is recognized by the endothelial cell leukocyte adhesion molecule ELAM-1. J. Biol. Chem. 266:14869-14872.

23. McNeil, P. L., A. L. Kennedy, A. S. Waggoner, D. L. Taylor, and R. F. Murphy. 1985. Light-scattering changes during chemotactic stimulation of human neutrophils: kinetics followed by flow cytometry. Cytometry. 6:7-12.

24. Lorant, D. E., K. D. Patel, T. M. McIntyre, R. P. McEver, S. M. Prescott, and G. Zimmerman. 1991. Coexpression of GMP-140 and PAF by endothelium stimulated by histamine or thrombin. A juxtacrine system for adhesion and activation of neutrophils. J. Cell Biol. 115:223-234.

25. Kriegler, M. 1991. Gene Transfer and Expression: A Laboratory Manual. W. H. Freeman, New York. 242 pp.

26. Schneider, C., R. A. Newman, D. R. Sutherland, U. Asser, and M. F. Greaves. 1982. A one-step purification of membrane proteins using a high efficiency immunomatrix. J. Biol. Chem. 257:10766-10769.

27. Moore, K. L., A. Varki, and R. P. McEver. 1991. GMP140 binds to a glycoprotein receptor on human neutrophils: evidence for a lectin-like interaction. J. Cell Biol. 112:491-499.

28. Dobrina, A., B. R. Schwartz, T. M. Carlos, H. D. Ochs, P. G. Beatty, and J. M. Harlan. 1989. CD11/CD18-independent neutrophil adherence to inducible endothelial-leucocyte adhesion molecules (E-LAM) in vitro. Immunology. 67:502-508.

29. DeFrees, S. A., W. Kosch, W. Way, J. C. Paulson, S. Sabesan, R. L. Halcomb, D.-H. Huang, Y. Ichikawa, and C.-H. Wong. 1995. Ligand recognition by E-selectin: synthesis, inhibitory activity, and conformational analysis of bivalent sialyl Lewis X analogs. J. Am. Chem. Soc. 117:66-79.

30. Picker, L. J., T. K. Kishimoto, C. W. Smith, R. A. Warnock, and E. C. Butcher. 1991. ELAM-1 is an adhesion molecule for skin-homing T cells. Nature (Lond.). 349:796-799.

31. Picker, L. J., S. A. Michie, L. S. Rott, and E. C. Butcher. 1990. A unique phenotype of skin-associated lymphocytes in humans: preferential expression of the HECA- 452 epitope by benign and malignant $\mathrm{T}$ cells at cutaneous sites. Am. J. Pathol. 136:1053-1068.

32. Price, T. H., H. D. Ochs, R. Gershoni-Baruch, J. M. Harlan, and A. Etzioni. 1995. In vivo neutrophil and lymphocyte function studies in a patient with leukocyte adhesion deficiency type II. Blood. 84:1635-1639.

33. Phillips, M. L., E. Nudelman, F. C. A. Gaeta, M. Perez, A. K. Singhal, 
S.-I. Hakomori, and J. C. Paulson. 1990. ELAM-1 mediates cell adhesion by recognition of a carbohydrate ligand, Sialyl-Le ${ }^{\mathrm{x}}$. Science (Wash. DC). 250:11301132.

34. Lowe, J. B., L. M. Stoolman, R. P. Nair, R. D. Larsen, T. L. Berhend, and R. M. Marks. 1990. ELAM-1-dependent cell adhesion to vascular endothelium determined by a transfected human fucosyltransterase cDNA. Cell. 63:475-484.

35. Walz, G., A. Aruffo, W. Kolanus, M. Bevilacqua, and B. Seed. 1990. Recognition by ELAM-1 of the sialyl-Le ${ }^{x}$ determinant on myeloid and tumor cells. Science (Wash. DC). 250:1132-1135.

36. Frydman, M., A. Etzioni, T. Eidlitz-Markus, I. Avidor, I. Varsano, Y. Shechter, J. B. Orlin, and R. Gershoni-Baruch. 1992. Rambam-Hasharon syndrome of psychomotor retardation, short stature, defective neutrophil motility and Bombay phenotype. Am. J. Med. Genet. 44:297-302.

37. Picker, L. J., R. A. Warnock, A. R. Burns, C. M. Doerschuk, E. L. Berg, and E. C. Butcher. 1991. The neutrophil selectin LECAM-1 presents carbohydrate ligands to the vascular selectins ELAM-1 and GMP-1 40. Cell. 66:921-933.

38. Spertini, O., F. W. Luscinskas, G. S. Kansas, J. M. Munro, J. D. Griffin M. A. Gimbrone, Jr., and T. F. Tedder. 1991. Leukocyte adhesion molecule-1 [LAM-I, L-selectin] interacts with an inducible endothelial cell ligand to support leukocyte adhesion. J. Immunol. 147:2565-2573.

39. Ley, K., T. F. Tedder, and G. S. Kansas. 1993. L-selectin can mediate leukocyte rolling in untreated mesenteric venules in vivo independent of E- or Pselectin. Blood. 82:1632-1638.

40. von Andrian, U. H., E. M. Berger, L. Ramezani, J. D. Chambers, H. D. Ochs, J. M. Harlan, J. C. Paulson, A. Etzioni, and K.-E. Arfors. 1993. In vivo behavior of neutrophils from two patients with distinct inherited leukocyte adhesion deficiency syndromes. J. Clin. Invest. 91:2893-2897.

41. Goelz, S. E., C. Hession, D. Goff, B. Griffiths, R. Tizard, B. Newman, G. Chi-Rosso, and R. Lobb. 1990. ELFT: a gene that directs the expression of an ELAM-1 ligand. Cell. 63:1349-1356.

42. Ohmori, K., T. Yoneda, G. Ishihara, K. Shigeta, K. Hirashima, M. Kanai, S. Itai, T. Sasaoki, S. Arii, H. Arita, and R. Kannagi. 1989. Sialyl SSEA-1 antigen as a carbohydrate marker of human natural killer calls and immature lymphoid cells. Blood. 74:255-261.

43. Ohmori, K., A. Takada, T. Yoneda, Y. Buma, K. Hirashima, K. Tsuyuoka, A. Hasegawa, and R. Kannagi. 1993. Differentiation-dependent expression of sialyl stage-specific embryonic antigen-1 and I-antigens on human lymphoid cells and its implications for carbohydrate-mediated adhesion to vascular endothelium. Blood. 81:101-111.

44. Munro, J. M., S. K. Lo, C. Corless, M. J. Robertson, N. C. Lee, R. L. Barnhill, D. S. Weinberg, and M. P. Bevilaqua. 1992. Expression of sialyl-lewis $\mathrm{X}$, an E-selectin ligand, in inflammation, immune processes, and lymphoid tissues. Am. J. Pathol. 141:1397-1408.

45. Carlos, T., N. Kovach, B. Schwartz, M. Rosa, B. Newman, E. Wayner, C. Benjamin, L. Osborn, R. Lobb, and J. Harlan. 1991. Human monocytes bind to cytokine-induced adhesive ligands on cultured human endothelial cell: ELAM1 and VCAM-1. Blood. 77:2266-2271.

46. Larsen, E., A. Celi, G. E. Gilbert, B. C. Furie, J. K. Erban, R. Bonfanti, D. D. Wagner, and B. Furie. 1989. PADGEM protein: a receptor that mediates the interaction of activated platelets with neutrophils and monocytes. Cell. 59:305-312.

47. Aruffo, A., W. Kolanus, G. Walz, P. Fredman, and B. Seed. 1991. CD62/ P-selectin recognition of myeloid and tumor cell sulfatides. Cell. 67:35-44.

48. Moore, K. L., N. L. Stults, S. Diaz, D. F. Smith, R. D. Cummings, A Varki, and R. P. McEver. 1992. Identification of a specific glycoprotein ligand for P-selectin (CD62) on myeloid cells. J. Cell Biol. 118:445-456.

49. Sako, D., X.-J. Chang, K. M. Barone, G. Vachino, H. M. White, G. Shaw, G. M. Veldman, K. M. Bean, T. J. Ahern, B. Furie, et al. 1993. Expression cloning of a functional glycoprotein ligand for P-selectin. Cell. 75:1179-1186.

50. Steegmaier, M., A. Levinovitz, S. Isenmann, E. Gorges, M. Lenter, H. P. Kocher, B. Kleuser, and D. Vestweber. 1995. The E-selectin-ligand ESL-1 is a variant of a receptor for fibroblast growth factor. Nature (Lond.). 373:615-620.

51. Skubitz, K. M. and R. W. Snook II. 1987. Monoclonal antibodies that recognize lacto- $N$-fucopentaose III (CD15) react with the adhesion-promoting glycoprotein family (LFA-1/HMAC-1/GP 150,95) and CR1 on human neutrophils. J. Immunol. 139:1631-1639.

52. Simon, S. I., J. D. Chambers, E. Butcher, and L. A. Sklar. 1992. Neutrophil aggregation is $\beta_{2}$-integrin- and $\mathrm{L}$-selectin-dependent in blood and isolated cells. J. Immunol. 149:2765-2771.

53. Rochon, Y. P., S. I. Simon, E. B. Lynam, and L. A. Sklar. 1994. A role for lectin interactions during human neutrophil aggregation. J. Immunol. 152:1385-1393.

54. Labow, M. A., C. R. Norton, J. M. Rumberger, K. M. Lombard-Gillooly, D. J. Shuster, J. Hubbard, R. Bertko, P. A. Knaack, R. W. Terry, M. L. Harbison, et al. 1994. Characterization of E-selectin-deficient mice: demonstration of overlapping function of the endothelial selectins. Immunity. 1:709-720. 